\title{
A School-Based Mobile App Intervention for Enhancing Emotion Regulation in Children: Exploratory Trial
}

Bettina Moltrecht ${ }^{1,2}, \mathrm{PhD}$; Praveetha Patalay ${ }^{3}, \mathrm{PhD}$; Jessica Deighton ${ }^{1}, \mathrm{PhD}$; Julian Edbrooke-Childs ${ }^{1}, \mathrm{PhD}$

${ }^{1}$ Evidence-based Practice Unit, University College London \& Anna Freud National Centre, London, United Kingdom

${ }^{2}$ Department of Psychiatry, University of Oxford, Oxford, United Kingdom

${ }^{3}$ MRC Unit for Lifelong Health and Ageing, University College London, London, United Kingdom

\section{Corresponding Author:}

Julian Edbrooke-Childs, PhD

Evidence-based Practice Unit

University College London \& Anna Freud National Centre

4-8 Rodney Street

London, N1 9JH

United Kingdom

Phone: 440207794 ext 2313

Email: Julian.childs@annafreud.org

\section{Abstract}

Background: Most mental health disorders are first experienced in childhood. The rising rates of mental health difficulties in children highlight the need for innovative approaches to supporting children and preventing these difficulties. School-based digital interventions that address shared risk factors and symptoms, such as emotion dysregulation, present exciting opportunities to enhance mental health support for children on a larger scale.

Objective: This study investigates the use of a new app-based intervention designed to support children's emotion regulation in schools. The aim is to optimize the usability, acceptability, and utility of the app and explore its scope for implementation with the target user in the school context.

Methods: As part of an interdisciplinary development framework, the app is being evaluated in a 3-month trial across 4 primary schools. In total, 144 children (aged 10-12 years) took part and accessed the intervention app in the classroom or at home. Outcomes regarding usability, acceptability, and implementation opportunities were assessed through digital user data, self-report questionnaires $(132 / 144,91.6 \%)$, and semistructured interviews with children $(19 / 144,13.2 \%)$ and teachers $(6 / 8,75 \%)$.

Results: The app usage data showed that $30 \%$ (128/426) of the users were returning users. Self-report data indicated that $40.1 \%$ $(53 / 132)$ of the children had not used the app, whereas $57.5 \%(76 / 132)$ had used it once or more. Of the children who had used the app, 67\% (51/76) reported that the app was helpful. Interviews with children and teachers suggested positive experiences with the app and that it helped them to calm down and relax. Children reported that they perceived the app as acceptable, usable, and helpful. In terms of the intervention's usability, most features functioned well; however, certain technical issues were reported, which may have led to reduced engagement levels. Teachers not only reported overall positive experiences but also discussed access difficulties and reported a lack of content as one of the main barriers to implementing the app. Having a web-based app significantly enhanced accessibility across devices and settings and provided teachers with more opportunities to use it. We identified the need for new, activating app features in addition to the existing, primarily relaxing ones. The findings indicated that it is possible to use and evaluate an app intervention in the school context and that the app could help enhance children's emotion regulation. We discuss areas for improvement regarding the app, study design, and future implementation strategies.

Conclusions: We share important insights with regard to the development, implementation, and evaluation of a new app for supporting children's emotion regulation in schools. Our results demonstrate that mental health apps represent a promising means to facilitate effective mental health service provision in and outside of the school context. Important lessons learned are shared to support other researchers and clinicians on similar journeys.

(JMIR Mhealth Uhealth 2021;9(7):e21837) doi: 10.2196/21837

\section{KEYWORDS}

emotion regulation; digital mental health; mhealth; school intervention; child mental health; mobile phone 


\section{Introduction}

\section{Background}

Approximately $10 \%-20 \%$ of children and young people worldwide experience mental health problems, making it one of the leading causes of disability in this population [1-3]. Considering the significant impact of mental health problems on other developmental outcomes (eg, academic achievement and physical health) [4,5], human and economic costs are substantial, calling for new, innovative approaches to support children and to prevent this problem. To address this challenge, this study explores the use of a newly developed web-based app as a universal school intervention to support children's mental health and well-being by strengthening their emotion regulation skills.

Schools have long been identified as an ideal setting to provide youth mental health support [6,7] because of the considerable amount of time children spend at school. Moreover, it has been suggested that implementing mental health interventions in schools can help overcome important social and environmental barriers to accessing mental health services, such as costs, family demographic factors, transport, and social stigma [8,9]. Evidence from 52 systematic reviews and meta-analyses has suggested that schools are key facilitators for the development and implementation of effective mental health interventions [10]. However, environment-specific challenges, such as increased pressure on teachers to meet academic targets, are pertinent to the implementation of new interventions in schools. Thus, interventions that require a significant amount of time and effort from teachers are often discarded [11]. Digital interventions provide an effective means to overcome such challenges, as they minimize costs, time, and personal resources in comparison with face-to-face interventions [11].

\section{Digital Mental Health Interventions for Children and Young People}

Digital mental health interventions have received increasing attention in recent years [12], with growing evidence supporting their effectiveness in clinical and community settings $[13,14]$. Owing to the rapid and consistent progress of technology, children and young people are increasingly adopting mobile apps, and their usage should therefore be considered in today's youth mental health provision. We built on these developments and designed a new web-based app to support children in the school context, which remains widely underexplored. To date, only a few app interventions have been developed and evaluated, specifically for children and young people $[15,16]$, and even less so in the school setting, with some exceptions [17]. Early findings from this research indicated that school mental health apps were perceived as potentially useful. However, they also highlighted that future studies need to focus more on refining and adjusting digital interventions to meet young users' needs and make them suitable for the context in which they are being delivered [18]. In line with this, it was highlighted that an iterative approach of testing, evaluating, and refining is integral to the development and design of digital interventions.
Newer evaluation guidelines for digital interventions consistently emphasize that any early evaluation attempts should focus on optimizing a digital intervention to ensure adequate levels of usability, acceptability, and engagement before any feasibility or efficacy testing [19,20]. Given that effectiveness trials are highly resource demanding, it is recommended that researchers follow a staged and iterative evaluation process [21], particularly with digital interventions. Digital interventions come with an added layer of complexity due to the underlying technology, which needs to be tested for its stability and usability first, as any issue with the technology would otherwise have a tremendous effect on the intervention's implementation success and effectiveness as a whole [22,23]. Pursuant to this, the primary aim of this study is to optimize the existing app intervention by exploring its usability and acceptability from a user's perspective as well as the possibility of implementing and evaluating it within the school context.

A closer look at the digital mental health landscape indicates that most interventions aim to support specific mental health disorders or symptoms $[6,13,18]$. However, especially in children where comorbidity rates (ie, transitioning between disorders and showing symptoms from more than one disorder) are high, it has been shown that transdiagnostic interventions are not only highly beneficial for this group but also that traditional psychological interventions can be further improved by adding a transdiagnostic focus [24]. Furthermore, transdiagnostic interventions have also been regarded as highly suitable for the school context, as they reduce the burden on teachers having to deliver multiple, highly fragmented, targeted interventions [25].

Evidence suggests that emotion regulation is an important transdiagnostic mechanism that underlies a wide range of mental health disorders and predicts later levels of psychopathology. Emotion regulation can be described as the extrinsic and intrinsic processes through which individuals monitor, evaluate, and modify emotional reactions to accomplish their goals [26]. There has been an increasing interest in emotion regulation as a treatment and prevention target because of growing evidence demonstrating that emotion regulation difficulties are not only present in most mental health disorders but are also a significant risk factor for future mental health difficulties [27,28]. This is supported by a number of systematic reviews [29] and meta-analyses [30,31], which have indicated that positive changes in emotion regulation are associated with a reduction in anxiety, depression, substance abuse, eating, and borderline personality disorder symptoms.

However, most digital mental health interventions have been developed for specific disorders, thereby leaving a significant gap in technologies addressing transdiagnostic factors such as emotion regulation. Although this could ultimately support a wider range of mental health problems, it is also highly suitable for the school context [32]. Most existing digital emotion regulation interventions have focused on emotion regulation deficits specific to either autism spectrum disorders or attention-deficit/hyperactivity disorder [33,34]. Although it has been shown that these interventions could potentially improve some of the specific deficits [35-37], the interventions were specifically designed for this unique population, thereby making 
it difficult to transfer them to a wider population. A very limited amount of research has explored the use of mobile apps to enhance emotion regulation in young people more generally [38] or as a means to prevent difficulties from arising. One exception is the new music app by Hides et al [38], which aims to enhance emotion regulation in adolescents and young adults. Their initial findings based on 169 young people (age=16-25) suggested that the app could potentially enhance emotion regulation in this population; however, further testing is required to determine its effectiveness.

To the best of our knowledge, there is currently no app intervention that targets emotion regulation in late childhood or preadolescence, despite an increasing number of scholars highlighting this period as a critical developmental stage to achieve maximum effect [39] in terms of youth mental health prevention. More specifically, past evidence has indicated that the median onset for most mental health disorders lies at the age of 11 years [40], with the majority reaching a peak during adolescence [41]. Recent developmental models suggest that adolescents are particularly prone to developing social-emotional disorders, which are triggered by a combination of developmental changes and preadolescent risk factors related to emotion regulation [39]. It has been argued that developmental changes hamper important emotion regulation processes, which subsequently lead to increased mental health difficulties later in adolescents [42]. Moreover, in the United Kingdom and many other countries, late childhood is marked by a transition period in which children have to leave primary school to enter secondary school. This period is frequently experienced as highly stressful by children [43], thereby supporting our case to strengthen children's emotion regulation before this significant transition period.

Taken together, we believe that by addressing emotion regulation during childhood, our app intervention presents a promising means not only to prevent mental health difficulties from arising but also to serve as an early intervention tool for children who might already be experiencing such difficulties.

\section{This Study}

There is a significant lack of digital mental health interventions for children that target important transdiagnostic factors, such as emotion regulation. The development of an acceptable, usable, and engaging emotion regulation app, which can be implemented successfully in the school context, will be highly beneficial for supporting children's mental health on a larger scale. Therefore, this study explores and evaluates the use of a new emotion regulation app for children with the primary aim of optimizing it further and informing future development stages with the ultimate goal of making it highly suitable for the user group and context [18].

The following research questions are addressed:

1. How acceptable and usable is the app from the children's perspective in the school context?

2. How do children interact and engage with the app at school?

3. What are the perceived barriers to and facilitators of implementing and delivering the intervention in the school context?
4. How can the existing app intervention be further improved? 5. What possibilities, facilitators, and barriers exist in terms of evaluating the app in the school setting?

\section{Methods}

\section{Recruitment and Participants}

The study was advertised on the Anna Freud National Centre for Children and Families organization's website and in a newsletter that was sent out monthly to a network of schools and related organizations across the United Kingdom. Newsletter recipients had previously signed up to receive newsletters. Initially, 19 schools indicated an interest in participation. Of the 19 schools, 11 were primary schools and were invited to an initial phone call. During the initial phone call, we discussed the research project and intervention as well as the schools' involvement if they agreed to take part in it. Only primary schools in the United Kingdom with access to tablets and wireless internet were eligible. Following the initial phone call, 4 schools were excluded: 3 were not primary schools and one had no phone or tablet policy. Three other schools stepped down before the start of the trial for the following reasons: (1) the research aspect of the intervention would take up too much time, (2) for a large percentage of parents, English was not their first language; hence, they struggled to understand the consent forms or information sheets, and (3) a lack of parental engagement.

Ultimately, 4 primary schools participated in this trial. Only children between the ages of 10 and 12 years with parental consent and child assent were eligible to participate, which resulted in data of 144 children at baseline and 132 children postintervention. Children's ages ranged between 10 and 11 years (mean 10.5, SD 0.49). Of the total sample, 56.3\% (81/144) indicated that they were White, $6.9 \%(10 / 144)$ were Black, $18.8 \%(27 / 144)$ were Asian, $15.3 \%$ (22/144) were mixed, and $2.8 \%(4 / 144)$ chose other as their ethnicity. Of the 144 children taking part, $166(81.1 \%)$ children indicated that English was their first language, $25(17.4 \%)$ children were not, and $2(1.4 \%)$ children preferred not to provide that information. A total of 6 female teachers participated in postintervention interviews; 2 teachers from 1 school were not available because of their illness.

\section{Intervention}

\section{Intervention Development and Design Process}

The app has been designed as a school-based universal intervention for children at the end of their primary school years (age: 10-12 years). The app is considered as a complex mental health intervention as it involves a set of multiple, interconnected, and interacting components [44,45]. As part of the development process, we created a new design and development framework based on the Medical Research Council (MRC) framework [44,46], the Patient-Clinician-Designer Framework [47], and the co-operative inquiry framework to co-design with children by Druin [48].

At this stage, we only focused on the first three phases of the MRC framework: theory, modeling, and exploratory trials. The theory stage concerns the exploration of relevant theory and a 
review of existing evidence to ensure that the most reliable intervention components are chosen. The intervention modeling stage suggests that the researchers focus on identifying potential underlying mechanisms that influence the preferred outcome, which are then included in the intervention. Following the design of the initial intervention, the researcher is advised to explore its components further through exploratory trials to identify constant and variable components, including acceptability of intervention, compliance, delivery, recruitment, and retention rate.

The MRC framework provides valuable guidelines for the development and evaluation of complex interventions; however, it provides little information with regard to the actual design of appropriate content [49]. Hence, we drew on two other frameworks rooted in the field of human-computer interaction and design. The Patient-Clinician-Designer Framework provides guidance on the design structure and content creation process of digital interventions for mental illness [47]. It aims to meet the complex requirements when designing user-centered interventions for mental illness by considering different perspectives (eg, in this study, teachers, parents, and children) and design goals.
As our main target group is children, we also drew on the co-operative inquiry framework by Druin [48], which provides specific techniques on involving young users in the design process of technologies. The co-operative inquiry framework highlights the importance of involving children as partners in the whole process, instead of merely letting them test the almost finished prototype or end product. Druin $[48,50]$ also emphasizes on the benefits of conducting fieldwork (ie, contextual inquiry), especially when working with children, which allows researchers to detect relevant contextual information, including patterns of activities, ways of communication and other artifacts. In addition, it has been reported that discussing design features in the relevant context (eg, school or home) makes it easier for children to express ideas and provide suggestions.

By combining the three frameworks from different fields, we hope to ensure a truly interdisciplinary approach to developing the app, the lack of which has been frequently criticized in many digital interventions [16,51]. Our development framework consisted of three stages, with each stage using a unique set of objectives, methodologies, and stakeholders (Figure 1). A more detailed description of the development and design process was published as a preprint by the first author (BM) and can be found in a study by Moltrecht et al [52].

Figure 1. The 3-stage interdisciplinary development process, including research activities and stakeholders.

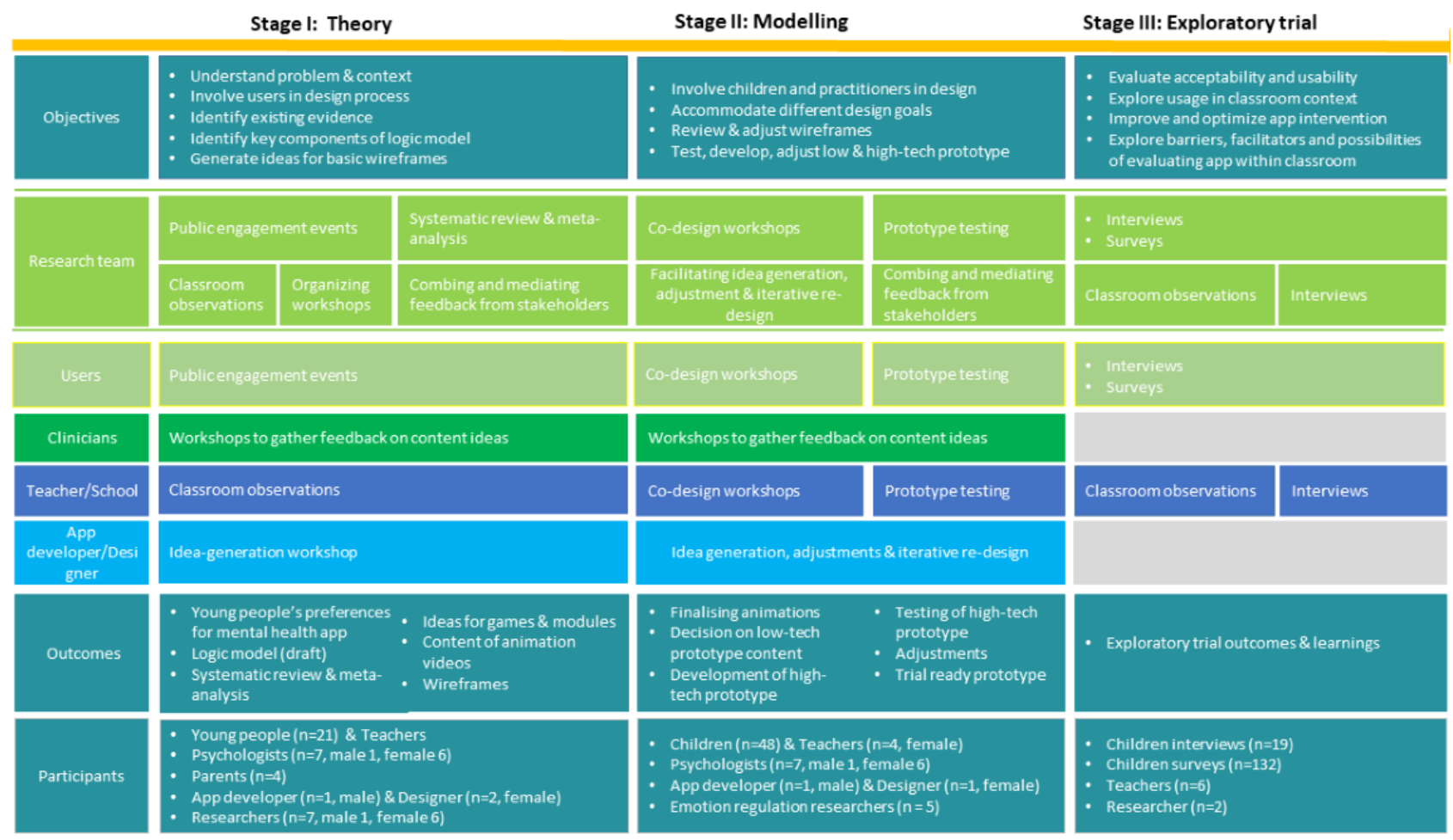

\section{Intervention Description}

During the onboarding process, users were presented with a video that explains the purpose of the app and its usage. Next, the user was guided through a process to set up an account and then select a preferred color scheme and profile picture.

Once the user entered the home screen, they could choose from four modules: play (including four games), relax (includes mindfulness and relaxation exercises), watch (includes psychoeducational animations), and tools (includes a list of emotion regulation strategies), which provide users with the opportunity to learn, practice, and develop new emotion regulation skills (Figure 2, Figure 3). The content is presented through audio tracks, images, animated films, and games. A more detailed presentation of each module can be found in Multimedia Appendix 1 as well as the following preprint, which was published in a study by Moltrecht et al [52]. 
Figure 2. Home screen of the app with 4 main modules and the activated digital agent showing the "tell me something" and "check-in" function.

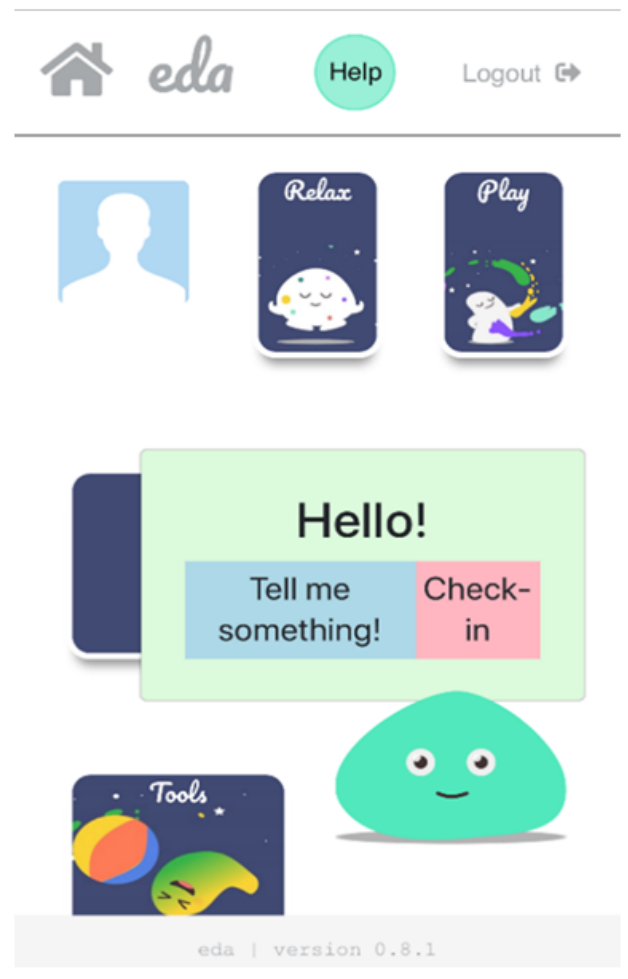

Figure 3. In-app content of the "play", "relax", and "watch" modules.
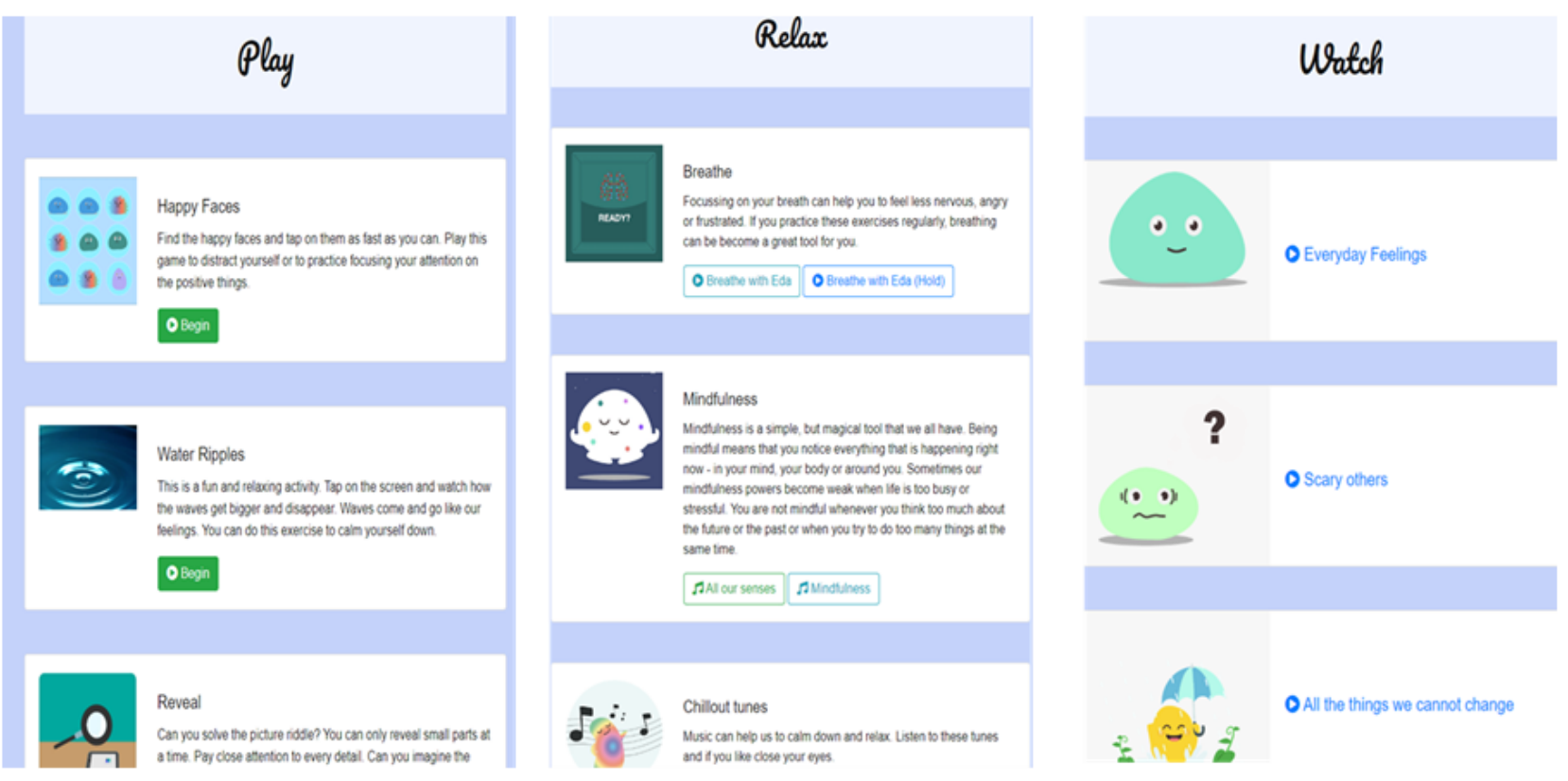

An animated agent is located at the bottom-right corner of the home screen and opens two more features when the user taps on it. These features are (1) tell me something, which activates jokes and funny facts with the aim to increase levels of engagement; and (2) a check-in function, where users can select from a range of emotions about how they feel and are subsequently provided with more information about the particular feeling and suggestions for potentially helpful strategies (Figure 4). 
Figure 4. Check-in function in the app with "feeling frustrated" being selected.

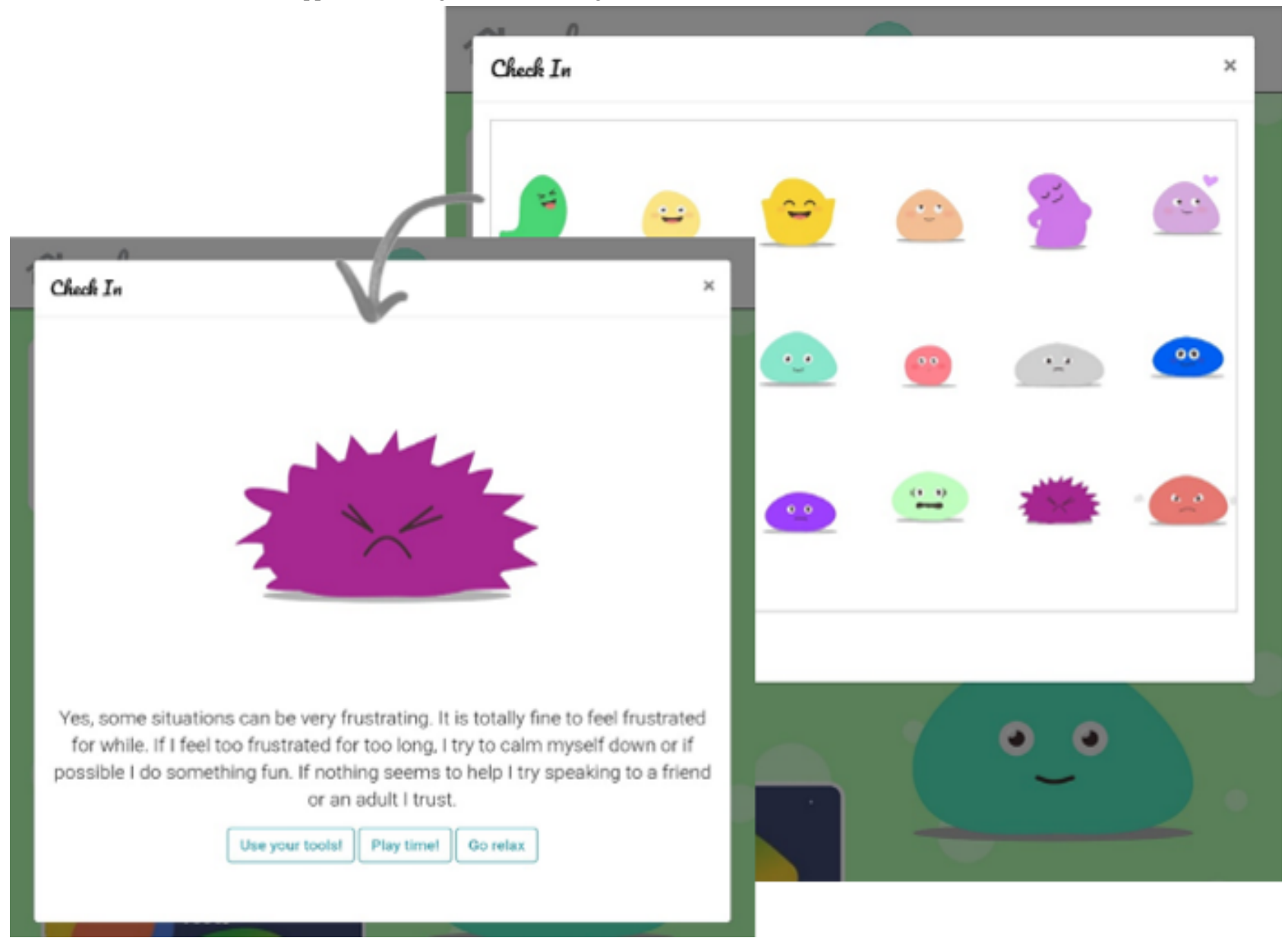

Teachers and children were instructed to freely explore different ways of using the app intervention. By providing them with the link to the app, it was also possible for children to explore the app outside the school context if they wanted to. This flexible approach was adopted so that children and teachers could use the intervention in their preferred ways and hopefully perceive it as less of a burden. Furthermore, we expected this to increase our understanding about app usage and implementation in future trials.

\section{Technical Specifications}

The intervention was developed as a responsive web-based app, which was believed to increase the accessibility of the app, as it allowed users to access it across different mobile devices, as well as desktop computers and smartboards. Although it worked across multiple platforms, it was optimized for tablets, as young children are more likely to have access to tablets at school and at home [53].

The app is delivered through the browser, meaning over-the-wire updates can be pushed out instantly, and the app uses advanced HTML5, CSS3, and JavaScript (ES6) techniques to render a smooth and performant user experience. The underlying development platform used was Meteor.js, a full-stack Node.js application development framework, hosted on a resilient AWS EC2 (Amazon Elastic Compute Cloud) instance with a MongoDB database hosted via MongoDB Atlas. The app only requires an internet connection when users access it for the first time, after which it can be saved to the home screen of the device. This feature was chosen to mitigate the risk that the intervention could not be accessed when schools had reduced or limited Wi-Fi infrastructure. The app does not store any individual user data and adheres to the existing general data protection regulations.

\section{Measures}

\section{Demographics}

Children reported age, gender, ethnicity, and their primary language spoken.

\section{Internalizing and Externalizing Symptoms}

The Short Mood and Feelings Questionnaire consists of 13 items that assess depressive symptoms in children and adolescents [54]. The Short Mood and Feelings Questionnaire has been shown to have good construct and internal validity across clinical (Cronbach $\alpha=.85$ ) and community samples [55]. Furthermore, 5 items ("I get very angry," "I lose my temper," "I hit out when I am angry," "I do things to hurt people," and "I break things on purpose") of the Me \& My Feelings Questionnaire were added to assess externalizing symptoms [56]. The Me \& My Feelings Questionnaire was developed as a self-reported mental health measure for the school setting and has been shown to have good psychometric properties across clinical and community samples (Cronbach $\alpha=$.78-.82) [56,57]. Items on both scales were rated on a 3-point Likert scale, ranging from "Not true" (1), "Sometimes" (2), and "True" (3). 
With both scales combined, scores ranged between 18 and 54, with higher scores indicating greater levels of symptoms.

\section{Well-being}

The Satisfaction with Life Scale for Children [58] was used to assess participants' personal perceptions of their well-being and satisfaction in life. The Satisfaction with Life Scale for Children consists of five items that are rated on a 5-point Likert scale, ranging from "disagree a lot" (1) to "agree a lot" (5) and has been reported to have good psychometric properties (Cronbach $\alpha=.84$ [58]). Higher scores indicated greater levels of satisfaction with life and well-being.

\section{Emotion Regulation}

The How I feel - Questionnaire is a multidimensional self-report scale to assess emotional arousal and regulation abilities in children. It consists of 30 items rated on a 5-point Likert scale ranging from "very true of me" (5) to "not at all true of me" (1). The items assess the frequency, intensity, and regulation of five different emotions: sadness, fear, anger, happiness, and excitement. There are three subscales: (1) a positive emotion subscale, where higher scores indicate that happiness and excitement are experienced with high frequency and intensity; (2) a negative emotion subscale with high scores indicating that fear, anger, and sadness are experienced with high frequency and intensity; and (3) an emotion regulation subscale, where high scores reflect a strong ability to regulate the frequency and intensity of either positive or negative emotions.

The How I feel - Questionnaire has been reported to be a reliable and valid measure (Cronbach $\alpha=.84-.90)$ for research and for school interventions targeting pupils' emotion regulation $[59,60]$.

\section{Engagement}

Engagement data were collected through Google Analytics and paper questionnaires, in which children were asked how often they had been using the app in the past 3 months.

Teachers were provided with a logbook, which they were asked to complete on a weekly basis to describe how often and in what way they used the app in their classrooms. Items in the logbook included (1) what was the average time or preferred way to use the app, (2) how did children engage with the app (eg, tablet or smartphone), (3) how often was the app used due to classroom disruptions, and (4) average time to reinstate children into the class after app use?

\section{Usability and Acceptability of App and Evaluation Measures}

To increase our understanding of the usability and acceptability of the app intervention, we conducted brief semistructured interviews with teachers and children after the 3-month intervention phase. A detailed interview schedule can be found in Multimedia Appendix 2. The interview assessed (1) what children and teachers thought about the app; (2) whether it was easy to use; (3) what aspects of the app they found helpful or unhelpful; and (4) how they used the app, what aspects of it, and in what situations.

The research team also explored the usability of the evaluation methods used. The researchers were present when the children filled in the questionnaires to observe if they experienced any difficulties when completing them. Furthermore, the research team kept a logbook of significant events and conversations with teachers or any reported difficulties during the study.

\section{Study Design and Procedure}

The University College London Research Ethics Committee approved this study (approval number: 7969/001).

Schools signed a memorandum of understanding, which explained the nature of the project and outlined the timeframes and responsibilities of the research team and the school. Parental consent, child assent forms, and parent and child information sheets were sent to the school and distributed by the class teacher. The research team visited the schools on the first day of the intervention to collect parent consent forms and child assent forms. Parents who indicated on the form that they had any remaining questions, where contacted by the research team to answer any remaining questions and obtain their oral consent over the phone, which was audio-recorded. Questionnaires were distributed to all participating children and the app was introduced to the class. After 6 weeks, the research team contacted the school to discuss the use of the app and any difficulties. Following a 3-month intervention phase, questionnaires were distributed again, and a researcher visited each classroom to observe the use of the app. Following this, semistructured interviews with 19 children and 6 teachers were conducted. Some teachers either had spoken to the children beforehand if they wanted to take part in the interviews or had asked the whole class in the presence of the researchers who would like to tell the researchers more about using the app at school. The research team highlighted to all children and teachers that honest answers were the most helpful and that they should not feel shy to report any negative experiences. All interviews with the children were audio-recorded with encrypted dictaphones and later transcribed. Owing to logistical issues, teacher interviews were not audio-recorded, and answers were written down by a researcher during the interview.

\section{Analytic Strategy}

\section{Quantitative Data}

Quantitative data from the questionnaires were used to calculate descriptive statistics for the baseline and postintervention assessments using SPSS (IBM Corporation).

Google Analytics data are presented below (Figure 5) to show overall usage and engagement. 
Figure 5. Engagement data as derived from Google Analytics.

Overview

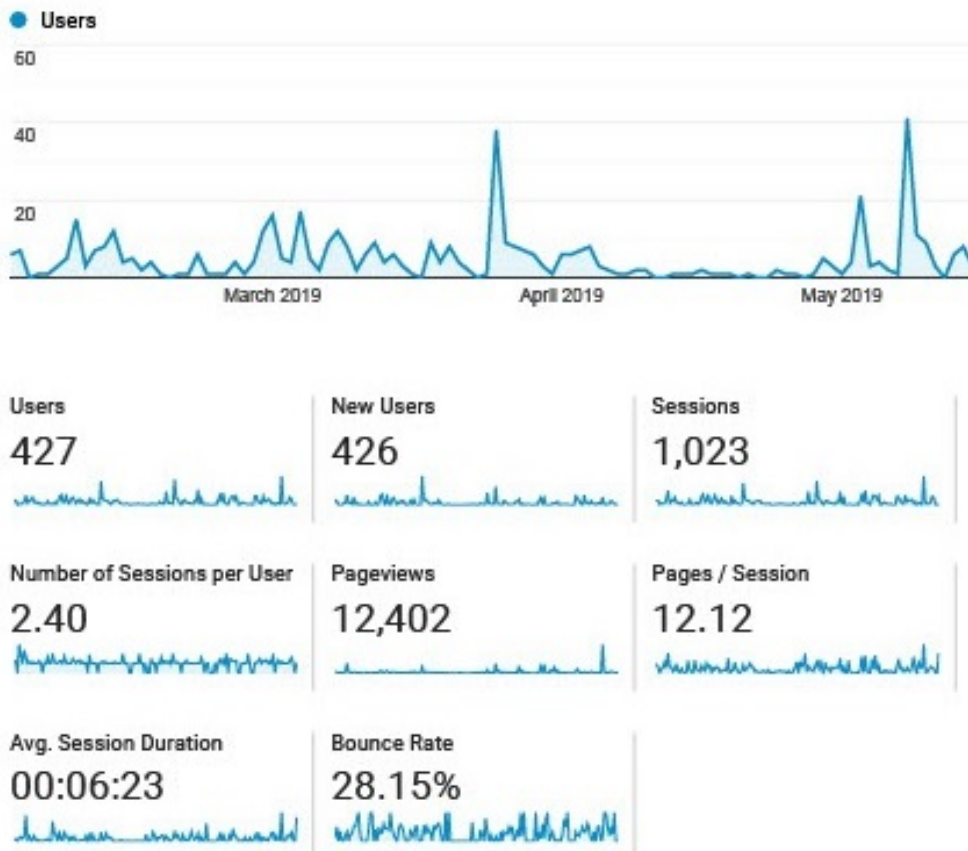

Participants section). In the final study, which included 4

\section{Qualitative Data}

The transcribed interviews and notes taken during the interviews were analyzed using thematic analysis [61].

Thematic analysis is a flexible method that can be used to analyze qualitative data by identifying patterns in the data. In this study, no existing framework was used but patterns were identified with the specific research questions regarding usability, acceptance, user-intervention interaction, and implementation in mind. Braun and Clarke [61] outlined 6 steps as a structured but flexible way to conduct thematic analysis (the article by Braun and Clarke [61] provides a detailed description of the six steps).

\section{Results}

\section{Participants, Recruitment, and Retention}

In total, 19 schools indicated an interest in taking part, of which we assessed 11 schools for their eligibility. Seven of these schools met our criteria and were eligible for participation. Of the seven eligible schools, 3 schools stepped down before the trial (see the reasons provided in the Recruitment and primary schools, a 57\% (4/7) retention rate was achieved.

In total, 144 children (female: $n=79$; male: $n=62$; not specified: $\mathrm{n}=3$ ) completed the surveys at baseline and 132 children completed the surveys postintervention, thereby resulting in an attrition rate of $91.6 \%(132 / 144)$.

Six out of eight teachers, all female, participated in the postintervention interviews. None of the teachers completed the weekly usage logbook.

\section{Mental Health and Emotion Regulation Measures}

The mean scores and SDs for pre- and postintervention assessments are presented in Table 1. Between 87.5\% (126/144) and $91.6 \%(132 / 144)$ of the children completed the measures at baseline and follow-up. Although the mean scores and SDs are comparable with those found in other population and community samples $[56,60,62]$, children in this study reported some difficulties with items on how they feel. Some children were unsure about the difference between items asking them about strong feelings and items asking them about powerful feelings. 
Table 1. Descriptive statistics for mental health and emotion regulation questionnaires ( $\mathrm{N}=144)$.

\begin{tabular}{|c|c|c|}
\hline Outcome & Participants, n (\%) & Score, mean (SD) \\
\hline $\mathrm{SMFQ}^{\mathrm{a}}$ baseline & $144(100)$ & $25.09(6)$ \\
\hline SMFQ postintervention & $132(91.6)$ & $24.22(5.99)$ \\
\hline SWLS-C ${ }^{b}$ baseline & $140(97.2)$ & $4.13(0.79)$ \\
\hline SWLS-C postintervention & $126(87.5)$ & $4.13(0.83)$ \\
\hline HIFQ-PES ${ }^{\mathrm{c}}$ baseline & $144(100)$ & $3.87(0.84)$ \\
\hline HIFQ-PES postintervention & $132(91.6)$ & $3.72(0.87)$ \\
\hline HIFQ-NES ${ }^{d}$ baseline & $144(100)$ & $2.11(0.79)$ \\
\hline HIFQ-NES postintervention & 132 (91.6) & $1.88(0.72)$ \\
\hline HIFQ-ERS ${ }^{\mathrm{e}}$ baseline & $144(100)$ & $3.37(0.83)$ \\
\hline HIFQ-ERS postintervention & $132(91.6)$ & $3.35(0.87)$ \\
\hline
\end{tabular}

${ }^{a}$ SMFQ: Short Mood and Feelings Questionnaire. Lower scores indicate fewer internalizing and externalizing difficulties.

${ }^{\mathrm{b}}$ SWLS-C: Satisfaction With Life Scale. Greater scores (maximum total score=5) indicate greater satisfaction with life.

${ }^{c}$ HIFQ-PES: How I feel - Questionnaire-Positive Emotion Scale. Greater scores indicate a greater frequency and intensity of happiness and excitement. ${ }^{\mathrm{d}}$ HIFQ-NES: How I feel - Questionnaire-Negative Emotion Scale. Greater scores indicate a greater frequency and intensity of sadness, anger, and anxiety.

${ }^{\mathrm{e}}$ HIFQ-ERS: How I feel - Questionnaire-Emotion Regulation Scale. Greater scores indicate the greater regulation of the frequency and intensity of emotions.

\section{Engagement}

In total, $57.5 \%(76 / 132)$ of all children from all schools indicated that they had used the app at least once, whereas $40.1 \%(53 / 132)$ indicated that they had never used the app in the past 3 months. At postassessment, 7.6\% (10/132) of the children reported that they had used the app weekly. Of the 76 children who indicated that they had used the app, $67 \%(51 / 76)$ said that they found it helpful, and 58\% (44/76) said that they would recommend the app to a friend.

No data were gathered through the teacher logbooks; therefore, we were unable to analyze any quantitative data on average usage times per classroom over the 12 weeks or in what way the app was engaged with over time.

Data collected via Google Analytics indicated that 426 users had accessed the website, of which $30 \%$ (128/426) were returning users and $70.2 \%$ (299/426) were new visitors. Furthermore, the average time spent on the app per session was 6 minutes and 22 seconds and the play module was most frequently visited, followed by relax and watch.

\section{Qualitative Outcomes}

\section{Children's Reported Usability and Acceptability}

In total, 19 children shared their experiences using the app during the interviews. Most children reported positive experiences with the app and provided insights regarding specific strengths and weaknesses.

\section{Feeling Calm and Relaxed}

Nearly all children reported that using the app made them feel calm and relaxed. They indicated using the app, especially during stressful times (eg, test at school, argument with friend or sibling, or having a bad day at school). Some children reported using the app to fall asleep at night. Children seemed to enjoy two features in particular, the Water Ripples game and the music function:

I think the app's helpful, um, if you're stressed or if you like, it's a good way to relax and you can use it to calm down.

\section{Helpfulness}

Most children reported that they found some of the features (ie, check-in function, videos, and tools list) particularly helpful and useful:
...the thing I also found was quite helpful was where you could sort of tell how you were feeling, and it sorta gave what you should do.

They explained that it increased their understanding or knowledge of their feelings and provided suggestions regarding possible solutions or actions to take:

...like it makes you understand it, your feelings are
something in you and it's ok to have them.

\section{Design and Technical Issues}

With respect to the app's limitations, the children most frequently reported technical or design issues. Most commonly mentioned were problems (eg, "didn't work," "too slow," or "took too long to load") related to the Reveal game and video clips, which appeared to happen more frequently on some devices than others (this was assumingly related to certain web-browsers). Furthermore, children mentioned that they would prefer to have more options to choose from for the color scheme and design of the home screen and other personalization features. 


\section{Feelings of Anger}

A few children reported that they found the app to be less helpful when they were very emotional or experiencing strong feelings of anger:

\section{I liked the app. Although it did not help me with my anger, no one could help me with this yet.}

In relation to this, one child explained that when they were angry, they preferred to "do something to kind of get it out" instead of engaging in calming or relaxing exercises.

\section{Children's Interaction With the Intervention}

Children reported different preferences for where, when, and how to use the app.

\section{Location}

Most children used the app at school where it was introduced to them. Some children reported using the app primarily during times when teachers allowed them to choose an activity for a certain amount of time. Other children said that they had agreed with their teacher to use it in certain situations when they struggled to concentrate or participate in class. Almost half of the children $(9 / 19,47 \%)$ reported that they also used the app at home.

\section{Emotional Prompts}

Many children suggested that the app is most suitable during stressful times or when someone struggles with their feelings. They provided examples, including having a fight with someone, not being able to concentrate, or feeling bored:

The best way to use the app is if you're stressed out, or um, if you need something to take your mind off something.

Children reported less frequent use of the app during less stressful times and when they felt generally happy:

It's not for someone who is happy, but some people get a bit angry sometimes, I'd recommend it to them.

\section{Design Prompts}

Although most children reported that the app was easy to use ("I just knew how to use it"), it became apparent that some features, such as the help function, had not been accessed or had not been discovered by them. Furthermore, children reported that they had forgotten about the app when they had not used it for a while.

\section{Access Barriers}

As the app was web-based, many children were not able to find or download the app through the app store, which they reported was their primary way to access apps. Hence, this was one of the major barriers to accessing the app. One child said, "I couldn't remember what it was called, so I couldn't find it."

Furthermore, in relation to the school setting, children reported difficulties accessing tablets as they were either not permanently available or locked in a drawer, so they had to ask for it. The latter was also perceived as a barrier, as children were too shy to request it and "didn't want to ask the teacher for it."

\section{Teacher-Reported Facilitators to and Barriers of Implementation and Delivery}

\section{Access Barriers}

Teachers also mentioned that the app was hard to find if the link was not available or in reach, which seemed to inhibit the use of the app from the teacher's perspective.

\section{Technical Issues}

Teachers reported experiencing technical issues of video crashing or content taking too long to load, which was perceived as a barrier to using it.

\section{Flexible Use}

Every teacher reported a slightly different way of using the app in their classroom, with some preferring a whole-class approach and others directing individuals to the app. The freedom to use the intervention in different ways was perceived as a facilitator, as it made it easier for them to find opportunities to use the app in the classroom.

\section{Compatibility With Teaching Style}

Teachers were more likely to use the app if they were compatible with their existing teaching methods and did not require additional work or adjustments. Moreover, teachers liked that they could direct children individually to the app, when needed, and that it "doesn't take away too much time from the teaching" or interrupts the classroom atmosphere.

Furthermore, in classrooms where mindfulness and relaxation exercises were already used in other ways, teachers reported to primarily use the relaxation module by projecting the exercises on the smartboard or playing the music, which seemed to "[help] to calm them [the children] down during work times."

In relation to this, teachers provided further app suggestions to support their teaching (eg, a timer and noise meter with a traffic light system to signal children when they are too noisy) and could therefore further facilitate the implementation of the app.

Teachers who did not see suitable opportunities to integrate the app in their teaching reported that it took them some time to "remember the app" and that there was a tendency to rely on "old habits" or methods in difficult situations ("in the heat of the moment"). They also reported feeling confident that using the app could become a habit.

\section{Recommendations for Further Improvements Content and Functionality}

Both children and teachers reported that they would like more content. Some children reported that they "got a bit bored" by having to play the same game. Others mentioned that there were "only four videos" to watch, which resulted in decreased interaction with the app over time. In line with this, teachers indicated that it was more likely that they continued using the app if there were updates that were more frequent, including new content.

Furthermore, children reported a wish for more features, such as making the embodied agent more responsive, so that more 
interactions are possible. One child compared it with "a robot that you can talk to."

\section{Individual Needs}

Some teachers mentioned that activating features, would be helpful "for children with too much energy," "when they are angry," or after "a long time of sitting." One teacher suggested the use of dance videos as an activating exercise during breaks.

In addition, teachers saw a need for more interventions that specifically support children with learning disabilities or autism spectrum disorder, as they seem to be more likely to experience specific emotion regulation difficulties associated with the disorder.

\section{Discussion}

\section{Acceptability and Usability of the App}

Through questionnaires and postintervention interviews, the present study collected data on the perceived usability and acceptability of the app. The interviews suggest that children perceived the app as acceptable, usable, and helpful. The interviews provided preliminary evidence that the app helped children to calm down and relax in stressful situations, and potentially increased their understanding and knowledge of emotions. However, this needs to be thoroughly tested in future studies.

Some children reported that they found the app to be less helpful when they experienced anger. This suggests that there is a need for different types of support with respect to different emotional experiences. A similar idea was suggested in past research with infants, whereby certain strategies (ie, distraction) were more effective in regulating anger than fear [63].

In terms of the intervention's usability, most parts of the intervention functioned well; however, certain technical issues were reported that led to reduced engagement levels. These issues must be addressed before future evaluations.

\section{Interaction and Engagement}

Children reported that they used the app primarily at school, whereas others accessed it at home. Most indicated that stressful situations were one of the main motives for accessing the app. Children and teachers did not receive specific instructions on how to use the app; therefore, differences occurred between classes, with some teachers directing certain children to the app in a special area in the classroom, whereas others used it primarily with the whole classroom. Children were provided with a link to the app at school and they could access it at home if they followed the same link. Although this made it more difficult to exactly track usage, the open approach helped us understand how and when children used the app depending on the context (eg, listening to music to concentrate in class vs listening to music to fall asleep at home).

Engagement data from Google Analytics suggested that $30 \%$ $(128 / 426)$ to $37.1 \%(158 / 426)$ of the users repeatedly accessed the app over a 3-month period. Although this number would ideally be higher, it is similar to adherence rates reported for other mental health apps [64].
In an attempt to mitigate low levels of engagement, one of the most common limitations in digital health interventions, we involved children and young people throughout the development and design of the app intervention. Interviews with the children indicated that the Water Ripples game was perceived as one of the most positive and helpful features in the app, which supports our interdisciplinary development approach.

With respect to children's and teachers' requests for having more content updates to maintain the level of novelty, future research could explore the use of timed updates, whereby sections of the content are released one after another. We recognize that this was only one piece of the puzzle. Issues surrounding user engagement are a recurring topic in the field, posing the question of how much engagement is actually needed for an intervention to be effective. The data from this study do not provide sufficient evidence to determine this, and further research is required.

Nevertheless, based on the children's reports, it can be assumed that some of the features positively influenced user engagement, such as the digital agent, which should be further explored (eg, chatbots and getting clothes or objects as rewards to change its appearance).

\section{Delivery and Implementation}

Teachers play a significant role in the intervention's implementation and delivery. Therefore, we tried to gain insights into potential barriers to and facilitators for implementing the app in a school setting.

Although teachers reported positive experiences, they also reported access difficulties and lack of content as the main barriers to implementing the intervention. Our findings suggest that teachers are more likely to use the app if they are compatible with their existing teaching methods. Teachers who saw fewer natural opportunities to integrate it reported more barriers to use the app. This is in line with previous research findings [18] and highlights the importance of considering teachers' perspectives when agreeing on design goals and intervention features. At the same time, teachers' requests and any subsequent design implications will have to be carefully considered in relation to the intervention's overall goal (ie, supporting children's emotion regulation) and any conflicting interests with young users' requests need to be mediated. For instance, although some teachers suggested features such as a noise meter, the research team needs to explore whether such a feature would primarily benefit teachers (eg, as a classroom management strategy) or young users as well.

Another barrier related to the school environment was the small number of tablets available per class, which limited the accessibility of the intervention. In addition, some schools only provided access to tablets upon request, thereby limiting ease of access. However, the possibility of accessing the app through other devices, such as computers or smartboards, enhanced the general uptake of the intervention in the school context. 


\section{Possibilities, Facilitators to, and Barriers of Conducting a School-Based App Evaluation}

Important conclusions can be drawn regarding the possibility of evaluating the app in a school setting. In terms of school recruitment, we retained $57 \%(4 / 7)$ of the originally recruited schools, which could be further improved. Schools reported that they feared that their resources were limited to facilitate the research. Furthermore, some schools reported that there were significant issues due to unmet translation needs, which suggests that translated information sheets and consent forms should be made available in a future trial. Some schools also mentioned that it would have been helpful if the research team had provided guidance that was more specific on the app usage or if the research team had explored different means to use the app with the teachers beforehand.

In terms of the measures used, a high number of questionnaires were completed at baseline and follow-up (baseline: 126/144, $87.5 \%$; follow-up: 132/144, 91.6\%), thereby suggesting acceptable completion rates. However, none of the teachers completed the weekly logbooks, and it was not possible to record any of the interviews with the teachers, which highlights specific barriers in terms of data collection from teachers.

Despite the identified barriers, the findings suggest that it is possible to implement and evaluate the app in a school setting. However, we suggest that a comprehensive feasibility trial is conducted next to ensure (1) an enhanced recruitment and assessment strategy, (2) improved integration of the app intervention in the school curriculum and teaching methods, and (3) easier access to the app by making it available on the app store. In line with this, we also suggest that a set of feasibility criteria is defined beforehand, so that informed decisions can be made as to whether an effectiveness trial is the next appropriate step [65].

\section{Considerations for Future App Features and Research}

In addition to the suggestions above, we would like to share further lessons learned, which will hopefully help improve the present and similar school-based app interventions.

\section{The School Setting}

With respect to one of the primary design goals and the prioritization of engagement, we opted for a multimedia app that included various audio and video materials. However, this partly presented itself as unsuitable for the school environment, as sounds can be disturbing or require access to headphones. This observation emphasizes that new types of interventions are accompanied by new challenges, which need to be explored further and taken into account.

\section{Specific Emotion Regulation App Features}

On the basis of previous research, we included a range of mindfulness and relaxation exercises [66], which children experienced as positive. Although mindfulness and relaxation apps have gained increased popularity, this study shows that for certain negative emotions, activating features instead of calming features could be equally important. These features seem to tap into a different set of emotion regulation strategies (eg, behavior activation and physical activity), which should not be neglected $[67,68]$. The finding that some children needed something else when they were angry is in line with emotion regulation research indicates that effective emotion regulation not only is merely about the frequency by which we apply certain strategies $[69,70]$ but also is about whether we have access to a diverse set of emotion regulation strategies that can be flexibly applied depending on the situation's demands $[71,72]$. This highlights the complexity of the emotion regulation construct, which is sometimes applied in an overly simplistic manner [73,74]. To account for this complexity, we chose to develop psychoeducational films to introduce children to the more complex concept of emotion regulation. Interviews showed that films could have the potential to increase children's understanding and knowledge of emotion regulation, but more research is needed to prove this.

Another important feature to enhance emotion regulation was the check-in function, which was designed to support children by accessing adaptive emotion regulation strategies and increasing their awareness of the diverse range of emotions. Research has shown that both are related to positive mental health outcomes [75-77]. Children in this study found this feature helpful and used it either as a guide to identify their feelings or to explore and learn about different strategies. We believe that this feature could also serve as an ideal assessment tool for collecting data about users' day-to-day feelings.

Concerning the help function, we found that many children had not used or seen it until a researcher mentioned it in the interview. After consulting the children, most agreed that it was a good idea to provide guided support for emotionally intense situations. However, they also explained that having it in the app did not address their needs in the situation, due to a lack of permanent or immediate access to a device. We suggest that future research could explore this idea further through wearable devices, which also provide an ideal opportunity to integrate advanced health technology concepts, such as just-in-time adaptive interventions [78].

\section{Strengths and Limitations}

A significant strength of this research concerns the development process of the app, for which we included children and young people at every stage and adopted a truly interdisciplinary approach [52]. Another strength relates to the collaborative approach with schools, which has various benefits. It ensured regular access to the user group and helped identify context-specific design goals at an early stage. Teachers also contributed tremendously to their views and expertise from working with the user group. The lack of teachers' roles as intervention deliverers is a limitation that needs to be addressed further. Furthermore, teachers had very limited time available; therefore, we suggest conducting more regular classroom observations to adjust the app for the classroom setting.

Finally, we would like to mention that in some cases, teachers played a significant role in selecting children for the interviews. Although we asked teachers to provide us with a representative sample, it is possible that teachers unconsciously selected children who were more likely to report positive aspects. This assumption is based on previous research showing that children with certain characteristics, such as lower academic achievement 
or greater externalizing tendencies, were less likely to be considered for taking part in research [79].

\section{Conclusions}

We explored the possibilities of using, implementing, and evaluating a new app intervention to improve children's emotion regulation abilities in the school context. The results suggest that the intervention presents a promising opportunity to enhance emotion regulation abilities by considering the complex nature of the construct itself. The app aims to assist children with their emotion regulation abilities by offering guidance in identifying feelings and selecting adaptive emotion regulation strategies.
The app was perceived as acceptable and usable, although some technological issues need to be addressed before any further evaluation. The data provided valuable insights regarding important facilitators and barriers to implementing and evaluating the app in the school setting. Important lessons learned are shared and will hopefully be beneficial in the development and evaluation of similar interventions. We hope that this work will motivate the development of further technology-based interventions that target transdiagnostic mechanisms such as emotion regulation in youth, as these are of particular importance considering the high comorbidity rates and less specific symptom profiles in children and young people.

\section{Acknowledgments}

BM received funding from the European Union's Horizon 2020 Research and Innovation Programme under the Marie Sklowdowska-Curie grant (grant 722561). The authors would like to thank all the schools, children, teachers, and parents who participated in this project.

\section{Authors' Contributions}

$\mathrm{BM}$ is a research fellow in the Evidence-Based Practice Unit at the University College London, United Kingdom, and conducted this research as part of her PhD. She received funding for this study from the European Union's Horizon 2020 Research and Innovation Programme under the Marie Skłodowska-Curie grant 722561. The European Union's Horizon 2020 Research and Innovation Programme had no role in the study design, collection, analysis, or interpretation of the data, writing the manuscript, or the decision to submit the paper for publication. BM was involved in conceptualizing, data collection, data analysis, writing, editing, and reviewing the manuscript. JD is a professor of the Evidence-Based Practice Unit at the University College London, United Kingdom. JD was involved in conceptualizing, writing, editing, and reviewing. PP is an associate professor at the MRC Unit for Lifelong Health and Ageing and the Center for Longitudinal Studies at University College London. PP was involved in conceptualizing, writing, editing, and reviewing. JEC is an associate professor at the Evidence-Based Practice Unit at the University College London, United Kingdom. JEC was involved in conceptualizing, writing, editing, and reviewing.

\section{Conflicts of Interest}

None declared.

\section{Multimedia Appendix 1}

Animation video showing an overview of app features and usage.

[MP4 File (MP4 Video), 29334 KB-Multimedia Appendix 1]

\section{Multimedia Appendix 2}

Interview script.

[DOCX File, $24 \mathrm{~KB}-$ Multimedia Appendix 2]

\section{References}

1. Patalay P, Gage SH. Changes in millennial adolescent mental health and health-related behaviours over 10 years: a population cohort comparison study. Int J Epidemiol 2019 Oct 01;48(5):1650-1664 [FREE Full text] [doi: 10.1093/ije/dyz006] [Medline: 30815691]

2. Erskine HE, Moffitt TE, Copeland WE, Costello EJ, Ferrari AJ, Patton G, et al. A heavy burden on young minds: the global burden of mental and substance use disorders in children and youth. Psychol Med 2014 Dec 23;45(7):1551-1563. [doi: $10.1017 / \mathrm{s} 0033291714002888]$

3. Kieling C, Baker-Henningham H, Belfer M, Conti G, Ertem I, Omigbodun O, et al. Child and adolescent mental health worldwide: evidence for action. Lancet 2011 Oct;378(9801):1515-1525. [doi: 10.1016/s0140-6736(11)60827-1]

4. Izard C, Fine S, Schultz D, Mostow A, Ackerman B, Youngstrom E. Emotion knowledge as a predictor of social behavior and academic competence in children at risk. Psychol Sci 2001 Jan;12(1):18-23 [FREE Full text] [doi: 10.1111/1467-9280.00304] [Medline: 11294223]

5. Catalino LI, Fredrickson BL. A Tuesday in the life of a flourisher: the role of positive emotional reactivity in optimal mental health. Emotion 2011 Aug;11(4):938-950 [FREE Full text] [doi: 10.1037/a0024889] [Medline: 21859208] 
6. Caan W, Cassidy J, Coverdale G, Ha M, Nicholson W, Rao M. The value of using schools as community assets for health. Public Health 2015 Jan;129(1):3-16. [doi: 10.1016/j.puhe.2014.10.006] [Medline: 25481543]

7. Stephan SH, Weist M, Kataoka S, Adelsheim S, Mills C. Transformation of children's mental health services: the role of school mental health. Psychiatr Serv 2007 Oct;58(10):1330-1338. [doi: 10.1176/ps.2007.58.10.1330] [Medline: 17914011]

8. Weist MD, Evans SW. Expanded school mental health: challenges and opportunities in an emerging field. J Youth Adolescence 2005 Feb;34(1):3-6. [doi: 10.1007/s10964-005-1330-2]

9. Memon A, Taylor K, Mohebati LM, Sundin J, Cooper M, Scanlon T, et al. Perceived barriers to accessing mental health services among black and minority ethnic (BME) communities: a qualitative study in Southeast England. BMJ Open 2016 Nov 16;6(11):e012337 [FREE Full text] [doi: 10.1136/bmjopen-2016-012337] [Medline: 27852712]

10. Weare K, Nind M. Mental health promotion and problem prevention in schools: what does the evidence say? Health Promot Int 2011 Dec 12;26 Suppl 1(suppl 1):29-69. [doi: 10.1093/heapro/dar075] [Medline: 22079935]

11. Bishop D, Bryant KS, Giles SM, Hansen WB, Dusenbury L. Simplifying the delivery of a prevention program with web-based enhancements. J Prim Prev 2006 Jul 9;27(4):433-444. [doi: 10.1007/s10935-006-0042-z] [Medline: 16763766]

12. Hollis C, Morriss R, Martin J, Amani S, Cotton R, Denis M, et al. Technological innovations in mental healthcare: harnessing the digital revolution. Br J Psychiatry 2015 Apr 02;206(4):263-265. [doi: 10.1192/bjp.bp.113.142612] [Medline: 25833865]

13. Pennant ME, Loucas CE, Whittington C, Creswell C, Fonagy P, Fuggle P, Expert Advisory Group. Computerised therapies for anxiety and depression in children and young people: a systematic review and meta-analysis. Behav Res Ther 2015 Apr;67:1-18. [doi: 10.1016/j.brat.2015.01.009] [Medline: 25727678]

14. Fridrici M, Lohaus A. Stress-prevention in secondary schools: online- versus face-to-face-training. Health Edu 2009 Jun 19;109(4):299-313. [doi: 10.1108/09654280910970884]

15. Grist R, Porter J, Stallard P. Mental health mobile apps for preadolescents and adolescents: a systematic review. J Med Internet Res 2017 May 25;19(5):e176 [FREE Full text] [doi: 10.2196/jmir.7332] [Medline: 28546138]

16. Hollis C, Falconer CJ, Martin JL, Whittington C, Stockton S, Glazebrook C, et al. Annual Research Review: Digital health interventions for children and young people with mental health problems - a systematic and meta-review. J Child Psychol Psychiatry 2017 Apr 10;58(4):474-503. [doi: 10.1111/jcpp.12663] [Medline: 27943285]

17. Edbrooke-Childs J, Smith J, Rees J, Edridge C, Calderon A, Saunders F, et al. An app to help young people self-manage when feeling overwhelmed (ReZone): protocol of a cluster randomized controlled trial. JMIR Res Protoc 2017 Nov 03;6(11):e213. [doi: 10.2196/resprot.7019]

18. Edridge C, Deighton J, Wolpert M, Edbrooke-Childs J. The implementation of an mHealth intervention (ReZone) for the self-management of overwhelming feelings among young people. JMIR Form Res 2019 May 02;3(2):e11958 [FREE Full text] [doi: 10.2196/11958] [Medline: 31045499]

19. Murray E, Hekler EB, Andersson G, Collins LM, Doherty A, Hollis C, et al. Evaluating digital health interventions: key questions and approaches. Am J Prev Med 2016 Nov;51(5):843-851 [FREE Full text] [doi: 10.1016/j.amepre.2016.06.008] [Medline: 27745684]

20. World Health Organization. Monitoring and Evaluating Digital Health Interventions: A Practical Guide to Conducting Research and Assessment. Geneva: World Health Organization; 2016:1-133.

21. Bardram JE, Frost M, Szántó K, Faurholt-Jepsen M, Vinberg M, Kessing LV. Designing mobile health technology for bipolar disorder: a field trial of the monarca system. In: Proceedings of the SIGCHI Conference on Human Factors in Computing Systems. 2013 Presented at: CHI Conference on Human Factors in Computing Systems; April 27-May 2, 2013; Paris France p. 2627-2636. [doi: 10.1145/2470654.2481364]

22. Coyle D, McGlade N, Doherty G, O'Reilly G. Exploratory evaluations of a computer game supporting cognitive behavioural therapy for adolescents. In: Proceedings of the SIGCHI Conference on Human Factors in Computing Systems. 2011 Presented at: CHI Conference on Human Factors in Computing Systems; May 7-12, 2011; Vancouver BC Canada p. 2937-2946. [doi: 10.1145/1978942.1979378]

23. Matthews M, Doherty G. In the mood: engaging teenagers in psychotherapy using mobile phones. In: Proceedings of the SIGCHI Conference on Human Factors in Computing Systems. 2011 Presented at: CHI Conference on Human Factors in Computing Systems; May 7-12, 2011; Vancouver BC Canada p. 2947-2956. [doi: 10.1145/1978942.1979379]

24. Taylor RD, Oberle E, Durlak JA, Weissberg RP. Promoting positive youth development through school-based social and emotional learning interventions: a meta-analysis of follow-up effects. Child Dev 2017 Jul 07;88(4):1156-1171. [doi: 10.1111/cdev.12864] [Medline: 28685826]

25. Greenberg MT, Weissberg RP, O'Brien MU, Zins JE, Fredericks L, Resnik H, et al. Enhancing school-based prevention and youth development through coordinated social, emotional, and academic learning. Am Psychol 2003 Jun;58(6-7):466-474. [doi: 10.1037/0003-066X.58.6-7.466]

26. Thompson RA, Goodman M. Development of emotion regulation: more than meets the eye. In: Kring AM, Sloan DM, Gross JJ, Werner KH, Thompson RA, editors. Emotion Regulation and Psychopathology: A Transdiagnostic Approach to Etiology and Treatment. New York, United States: Guilford Press; 2009:1-461.

27. Gross JJ, Muñoz RF. Emotion regulation and mental health. Clinical Psychology: Science and Practice 1995;2(2):151-164. [doi: 10.1111/j.1468-2850.1995.tb00036.x] 
28. Keenan K. Emotion dysregulation as a risk factor for child psychopathology. Clinical Psychology: Science and Practice 2000;7(4):418-434. [doi: 10.1093/clipsy.7.4.418]

29. Sloan E, Hall K, Moulding R, Bryce S, Mildred H, Staiger PK. Emotion regulation as a transdiagnostic treatment construct across anxiety, depression, substance, eating and borderline personality disorders: a systematic review. Clin Psychol Rev 2017 Nov;57:141-163. [doi: 10.1016/j.cpr.2017.09.002] [Medline: 28941927]

30. Aldao A, Nolen-Hoeksema S, Schweizer S. Emotion-regulation strategies across psychopathology: a meta-analytic review. Clin Psychol Rev 2010 Mar;30(2):217-237. [doi: 10.1016/j.cpr.2009.11.004] [Medline: 20015584]

31. Moltrecht B, Deighton J, Patalay P, Edbrooke-Childs J. Effectiveness of current psychological interventions to improve emotion regulation in youth: a meta-analysis. Eur Child Adolesc Psychiatry 2021 Jun 27;30(6):829-848 [FREE Full text] [doi: 10.1007/s00787-020-01498-4] [Medline: 32108914]

32. Forbes MK, Rapee RM, Krueger RF. Opportunities for the prevention of mental disorders by reducing general psychopathology in early childhood. Behav Res Ther 2019 Aug;119:103411 [FREE Full text] [doi: 10.1016/j.brat.2019.103411] [Medline: 31202004]

33. Sonne T, Jensen MM. ChillFish: A respiration game for children with ADHD. In: Proceedings of the TEI '16: Tenth International Conference on Tangible, Embedded, and Embodied Interaction. 2016 Presented at: TEI '16: Tenth International Conference on Tangible, Embedded, and Embodied Interaction; February 14-17, 2016; Eindhoven Netherlands p. 271-278. [doi: $\underline{10.1145 / 2839462.2839480]}$

34. Lobel A, Gotsis M, Reynolds E, Annetta M, Engels R, Granic I. Designing and utilizing biofeedback games for emotion regulation: the case of nevermind. In: Proceedings of the 2016 CHI Conference Extended Abstracts on Human Factors in Computing Systems. 2016 Presented at: CHI'16: CHI Conference on Human Factors in Computing Systems; May 7-12, 2016; San Jose California USA p. 1945-1951. [doi: 10.1145/2851581.2892521]

35. Lee CS, Lam SH, Tsang ST, Yuen CM, Ng CK. The effectiveness of technology-based intervention in improving emotion recognition through facial expression in people with autism spectrum disorder: a systematic review. Rev J Autism Dev Disord 2017 Dec 27;5(2):91-104. [doi: 10.1007/s40489-017-0125-1]

36. Grossard C, Grynspan O, Serret S, Jouen A, Bailly K, Cohen D. Serious games to teach social interactions and emotions to individuals with autism spectrum disorders (ASD). Comput Edu 2017 Oct;113:195-211. [doi: 10.1016/j.compedu.2017.05.002]

37. Park JH, Abirached B, Zhang Y. A framework for designing assistive technologies for teaching children with ASDs emotions. In: Extended Abstracts CHI '12 Conference on Human Factors in Computing Systems. 2012 Presented at: CHI '12: CHI Conference on Human Factors in Computing Systems; May 5-10, 2012; Austin Texas USA p. 2423-2428. [doi: $10.1145 / 2212776.2223813]$

38. Hides L, Dingle G, Quinn C, Stoyanov SR, Zelenko O, Tjondronegoro D, et al. Efficacy and outcomes of a music-based emotion regulation mobile app in distressed young people: randomized controlled trial. JMIR Mhealth Uhealth 2019 Jan 16;7(1):e11482 [FREE Full text] [doi: 10.2196/11482] [Medline: 30664457]

39. Rapee RM, Oar EL, Johnco CJ, Forbes MK, Fardouly J, Magson NR, et al. Adolescent development and risk for the onset of social-emotional disorders: a review and conceptual model. Behav Res Ther 2019 Dec;123:103501. [doi: 10.1016/j.brat.2019.103501] [Medline: 31733812]

40. Kessler RC, Amminger GP, Aguilar-Gaxiola S, Alonso J, Lee S, Ustun TB. Age of onset of mental disorders: a review of recent literature. Curr Opin Psychiatry 2007;20(4):359-364. [doi: 10.1097/yco.0b013e32816ebc8c]

41. Powers A, Casey BJ. The adolescent brain and the emergence and peak of psychopathology. J Infant Child Adolesc Psychother 2015 Mar 17;14(1):3-15. [doi: 10.1080/15289168.2015.1004889]

42. Dahl RE. Adolescent brain development: a period of vulnerabilities and opportunities. Keynote address. Ann N Y Acad Sci 2004 Jun;1021:1-22. [doi: 10.1196/annals.1308.001] [Medline: 15251869]

43. Zeedyk MS, Gallacher J, Henderson M, Hope G, Husband B, Lindsay K. Negotiating the transition from primary to secondary school. Sch Psychol Int 2016 Jun 29;24(1):67-79. [doi: 10.1177/0143034303024001010]

44. Campbell M, Fitzpatrick R, Haines A, Kinmonth AL, Sandercock P, Spiegelhalter D, et al. Framework for design and evaluation of complex interventions to improve health. Br Med J 2000 Sep 16;321(7262):694-696 [FREE Full text] [doi: 10.1136/bmj.321.7262.694] [Medline: 10987780]

45. Craig P, Dieppe P, Macintyre S, Michie S, Nazareth I, Petticrew M, Medical Research Council Guidance. Developing and evaluating complex interventions: the new Medical Research Council guidance. Br Med J 2008 Sep 29;337:a1655 [FREE Full text] [doi: 10.1136/bmj.a1655] [Medline: 18824488]

46. Craig P, Dieppe P, Macintyre S, Nazareth I, Petticrew M. Developing and evaluating complex interventions: an introduction to the new Medical Research Council guidance. In: Killoran A, Kelly MP, editors. Evidence-Based Public Health: Effectiveness and Efficiency. Oxfordshire, United Kingdom: Oxford University Press; 2009:1-592.

47. Marcu G, Bardram J, Gabrielli S. A framework for overcoming challenges in designing persuasive monitoring and feedback systems for mental illness. In: Proceedings of the 5th International ICST Conference on Pervasive Computing Technologies for Healthcare. 2011 Presented at: 5th International ICST Conference on Pervasive Computing Technologies for Healthcare; May 23-26, 2011; Dublin, Republic of Ireland p. 1-8. [doi: 10.4108/icst.pervasivehealth.2011.246097] 
48. Druin A. Cooperative inquiry: developing new technologies for children with children. In: Proceedings of the SIGCHI Conference on Human Factors in Computing Systems. 1999 Presented at: CHI99: Conference on Human Factors in Computing Systems; May 15-20, 1999; Pittsburgh Pennsylvania USA p. 592-599. [doi: 10.1145/302979.303166]

49. Corry M, Clarke M, While AE, Lalor J. Developing complex interventions for nursing: a critical review of key guidelines. J Clin Nurs 2013 Sep 29;22(17-18):2366-2386. [doi: 10.1111/jocn.12173] [Medline: 23551526]

50. Druin A. The role of children in the design of new technology. Behav Info Tech 2002 Jan;21(1):1-25. [doi: 10.1080/01449290110108659]

51. Orlowski SK, Lawn S, Venning A, Winsall M, Jones GM, Wyld K, et al. Participatory research as one piece of the puzzle: a systematic review of consumer involvement in design of technology-based youth mental health and well-being interventions. JMIR Hum Factors 2015 Jul 09;2(2):e12 [FREE Full text] [doi: 10.2196/humanfactors.4361] [Medline: 27025279]

52. Moltrecht B, Patalay P, Bear HA, Deighton J, Edbrooke-Childs J. Interdisciplinary development of a transdiagnostic mobile app to enhance children's emotion regulation: sharing insights and lessons learned. PsyArXiv. Preprint posted online on March 2, 2021. [FREE Full text] [doi: 10.31234/osf.io/ks7ag]

53. Children and parents: media use and attitudes report 2019. Ofcom. 2020. URL: https://www.ofcom.org.uk/research-and-data/ media-literacy-research/childrens/children-and-parents-media-use-and-attitudes-report-2019 [accessed 2021-06-12]

54. Angold A, Erkanli A, Silberg J, Eaves L, Costello EJ. Depression scale scores in 8-17-year-olds: effects of age and gender. J Child Psychol Psychiatry 2002 Nov;43(8):1052-1063. [doi: 10.1111/1469-7610.00232] [Medline: 12455926]

55. Sharp C, Goodyer IM, Croudace TJ. The Short Mood and Feelings Questionnaire (SMFQ): a unidimensional item response theory and categorical data factor analysis of self-report ratings from a community sample of 7-through 11-year-old children. J Abnorm Child Psychol 2006 Jun 29;34(3):379-391. [doi: 10.1007/s10802-006-9027-x] [Medline: 16649000]

56. Deighton J, Tymms P, Vostanis P, Belsky J, Fonagy P, Brown A, et al. The development of a school-based measure of child mental health. J Psychoeduc Assess 2013 Jun 20;31(3):247-257 [FREE Full text] [doi: 10.1177/0734282912465570] [Medline: 25076806]

57. Patalay P, Deighton J, Fonagy P, Vostanis P, Wolpert M. Clinical validity of the Me and My School questionnaire: a self-report mental health measure for children and adolescents. Child Adolesc Psychiatry Ment Health 2014;8(1):17 [FREE Full text] [doi: 10.1186/1753-2000-8-17] [Medline: 24963344]

58. Gadermann AM, Schonert-Reichl KA, Zumbo BD. Investigating validity evidence of the satisfaction with life scale adapted for children. Soc Indic Res 2009 Apr 28;96(2):229-247. [doi: 10.1007/s11205-009-9474-1]

59. Walden TA, Harris VS, Catron TF. How I feel: a self-report measure of emotional arousal and regulation for children. Psychol Assess 2003 Sep;15(3):399-412. [doi: 10.1037/1040-3590.15.3.399] [Medline: 14593841]

60. Ciucci E, Baroncelli A, Grazzani I, Ornaghi V, Caprin C. Emotional arousal and regulation: further evidence of the validity of the "How I feel" questionnaire for use with school-age children. J Sch Health 2016 Mar 02;86(3):195-203. [doi: 10.1111/josh.12370] [Medline: 26830506]

61. Braun V, Clarke V. Using thematic analysis in psychology. Qual Res Psychol 2006 Jan;3(2):77-101. [doi: 10.1191/1478088706qp063oa]

62. Lang J, Schmitz B. German translation of the satisfaction with life scale for children and adolescents. J Psychoeduc Assess 2019 Jun 11;38(3):291-304. [doi: 10.1177/0734282919849361]

63. Buss KA, Goldsmith HH. Fear and anger regulation in infancy: effects on the temporal dynamics of affective expression. Soc Res Child Dev 1998:359-374. [doi: 10.1111/j.1467-8624.1998.tb06195.x]

64. Torous J, Nicholas J, Larsen ME, Firth J, Christensen H. Clinical review of user engagement with mental health smartphone apps: evidence, theory and improvements. Evid Based Ment Health 2018 Aug 05;21(3):116-119. [doi:

10.1136/eb-2018-102891] [Medline: 29871870]

65. Edbrooke-Childs J, Edridge C, Averill P, Delane L, Hollis C, Craven MP, et al. A feasibility trial of power up: smartphone app to support patient activation and shared decision making for mental health in young people. JMIR Mhealth Uhealth 2019 Jun 04;7(6):e11677 [FREE Full text] [doi: 10.2196/11677] [Medline: 31165709]

66. Heppner WL, Spears CA, Vidrine JI, Wetter DW. Mindfulness and emotion regulation. In: Ostafin B, Robinson M, Meier B, editors. Handbook of Mindfulness and Self-Regulation. New York: Springer; 2015:107-120.

67. Pascual-Leone A, Gillespie NM, Orr ES, Harrington SJ. Measuring subtypes of emotion regulation: from broad behavioural skills to idiosyncratic meaning-making. Clin Psychol Psychother 2016 May 20;23(3):203-216. [doi: 10.1002/cpp.1947] [Medline: 25704129]

68. Livingstone KM, Srivastava S. Up-regulating positive emotions in everyday life: strategies, individual differences, and associations with positive emotion and well-being. J Res Pers 2012 Oct;46(5):504-516. [doi: 10.1016/j.jrp.2012.05.009]

69. Dixon-Gordon KL, Aldao A, De Los Reyes A. Repertoires of emotion regulation: a person-centered approach to assessing emotion regulation strategies and links to psychopathology. Cogn Emot 2015 Dec 07;29(7):1314-1325. [doi: 10.1080/02699931.2014.983046] [Medline: 25435338]

70. Aldao A, Sheppes G, Gross JJ. Emotion regulation flexibility. Cogn Ther Res 2015 Jan 1;39(3):263-278. [doi: $10.1007 / \mathrm{s} 10608-014-9662-4]$

71. Lougheed JP, Hollenstein T. A limited repertoire of emotion regulation strategies is associated with internalizing problems in adolescence. Soc Dev 2012:704-721. [doi: 10.1111/j.1467-9507.2012.00663.x] 
72. Aldao A, Nolen-Hoeksema S. The influence of context on the implementation of adaptive emotion regulation strategies. Behav Res Ther 2012 Aug;50(7-8):493-501. [doi: 10.1016/j.brat.2012.04.004] [Medline: 22659159]

73. Yoon J, Li S, Hao Y, Kim C. Towards emotional well-being by design: 17 opportunities for emotion regulation for user-centered healthcare design. In: Proceedings of the 13th EAI International Conference on Pervasive Computing Technologies for Healthcare. 2019 Presented at: PervasiveHealth'19: The 13th International Conference on Pervasive Computing Technologies for Healthcare; May 20-23, 2019; Trento Italy p. 351-355. [doi: 10.1145/3329189.3329227]

74. Aldao A. The future of emotion regulation research: capturing context. Perspect Psychol Sci 2013 Mar 27;8(2):155-172. [doi: 10.1177/1745691612459518] [Medline: 26172497]

75. Gonçalves SF, Chaplin TM, Turpyn CC, Niehaus CE, Curby TW, Sinha R, et al. Difficulties in emotion regulation predict depressive symptom trajectory from early to middle adolescence. Child Psychiatry Hum Dev 2019 Aug 28;50(4):618-630 [FREE Full text] [doi: 10.1007/s10578-019-00867-8] [Medline: 30689145]

76. Quoidbach J, Gruber J, Mikolajczak M, Kogan A, Kotsou I, Norton MI. Emodiversity and the emotional ecosystem. J Exp Psychol Gen 2014 Dec;143(6):2057-2066. [doi: 10.1037/a0038025] [Medline: 25285428]

77. Ciarrochi J, Heaven PC, Supavadeeprasit S. The link between emotion identification skills and socio-emotional functioning in early adolescence: a 1-year longitudinal study. J Adolesc 2008 Oct;31(5):565-582. [doi: 10.1016/j.adolescence.2007.10.004] [Medline: 18083221$]$

78. Nahum-Shani I, Smith SN, Spring BJ, Collins LM, Witkiewitz K, Tewari A, et al. Just-in-Time Adaptive Interventions (JITAIs) in mobile health: key components and design principles for ongoing health behavior support. Ann Behav Med 2018 May 18;52(6):446-462 [FREE Full text] [doi: 10.1007/s12160-016-9830-8] [Medline: 27663578]

79. Noll RB, Zeller MH, Vannatta K, Bukowski WM, Davies WH. Potential bias in classroom research: comparison of children with permission and those who do not receive permission to participate. J Clin Child Psychol 1997 Mar;26(1):36-42. [doi: 10.1207/s15374424jccp2601_4] [Medline: 9118174]

\title{
Abbreviations \\ AWS EC2: Amazon Elastic Compute Cloud \\ MRC: Medical Research Council
}

\author{
Edited by L Buis; submitted 16.09.20; peer-reviewed by S Byrne, S Hugh-Jones; comments to author 09.11.20; revised version received \\ 03.03.21; accepted 28.04.21; published 14.07.21 \\ Please cite as: \\ Moltrecht B, Patalay P, Deighton J, Edbrooke-Childs J \\ A School-Based Mobile App Intervention for Enhancing Emotion Regulation in Children: Exploratory Trial \\ JMIR Mhealth Uhealth 2021;9(7):e21837 \\ URL: https://mhealth.jmir.org/2021/7/e21837 \\ doi: $10.2196 / 21837$ \\ PMID: 34259642
}

CBettina Moltrecht, Praveetha Patalay, Jessica Deighton, Julian Edbrooke-Childs. Originally published in JMIR mHealth and uHealth (https://mhealth.jmir.org), 14.07.2021. This is an open-access article distributed under the terms of the Creative Commons Attribution License (https://creativecommons.org/licenses/by/4.0/), which permits unrestricted use, distribution, and reproduction in any medium, provided the original work, first published in JMIR mHealth and uHealth, is properly cited. The complete bibliographic information, a link to the original publication on https://mhealth.jmir.org/, as well as this copyright and license information must be included. 